\title{
The Effect of Static Stretching Hamstring on Increasing Hamstring Muscle Extensibility and Pelvic Tilt Angle on Hamstring Tightness
}

\author{
Melya Rossa ${ }^{\mathrm{a}}$, Gadis Meinar Saria ${ }^{\mathrm{a}}$, Dwikora Novembri Utomo ${ }^{\mathrm{a} *}$ \\ a melyarossa08@gmail.com \\ ${ }^{a}$ Master Program of Sport Health Science, Faculty of Medicine, Universitas Airlangga, Surabaya, Indonesia
}

\begin{abstract}
Background: The hamstring muscle is one of the lower extremity muscles that has shortened tendency. Shortening hamstring muscle, that called hamstring tightness, is associated with decreased extensibility of the hamstring muscles and pelvic tilt angle. Static stretching exercise is one of the stretching exercise methods that is used to increase hamstring muscle length.

Purpose: The purpose of this study was to determine the effect of static stretching exercise on hamstring muscle extensibility and pelvic tilt angle in hamstring tightness. Material/Methods: Quasi-experimental pre-test and post-test control group design. The subjects of this study were 28 male students, who were divided into 2 groups. The treatment group and control group both consisted of 14 people. the hamstring muscle extensibility will be measured by examining active knee extension (AKE) and pelvic tilt angle will be measured with an inclinometer, which will be evaluated in four weeks in both groups.

Result: Static stretching exercise had a significant effect on increasing the extensibility of hamstring muscles $(\mathrm{p}<0.05)$ when compared to the control group. Meanwhile, static stretching exercise does not have a significant effect on the pelvic tilt angle $(p>0.05)$ as well as the control group. Furthermore, there is no correlation between the value of hamstring muscle extensibility and pelvic tilt angle after the intervention $(\mathrm{p}>0.05)$.
\end{abstract}

Keywords: hamstring tightness; pelvic tilt angle; hamstring muscle extensibility; static stretching

\section{Introduction}

The hamstring muscle is a lower extremity muscle that has an important role in various activities and exercises. In addition, the hamstring muscles also experience several disorders that cause pain, limited joint range of motion, and functional decline. Hamstring muscle disorders that currently appear in various circles are a decrease in joint range of motion accompanied by a feeling of limitation in the back of the thigh called hamstring tightness. Hamstring tightness is a multidimensional condition that includes musculoskeletal insufficiency or imbalance, nervous tension, and lumbopelvic dysfunction (Hansberger et al., 2019).

The prevalence of hamstring tightness is quite high and there is an increasing incidence among adolescents, as shown by the prevalence in students in Nepal of $40.17 \%$. In addition, the prevalence of hamstring tightness 
at the University of Pradeniya Sri Lanka reaches $80 \%$. This case can also be seen at any age and does not always occur in athletes, but can occur in office workers and students (Alshammari et al., 2019).

Hamstring muscles that experience shortening in hamstring tightness are musculotendinous units that have a decreased ability to elongate due to a reduced number of sarcomeres, or reduced length or elasticity of connective tissue (Mhatre et al., 2013). This condition is associated with decreased extensibility of the hamstring muscles. In addition, the condition of hamstring tightness is also associated with the pelvic tilt angle, because the hamstring muscles have their origin at the pelvic sciatic tuberosity (Braman, et al., 2016). The recommended intervention for hamstring tightness is stretching exercises. Static stretching exercises are one of the most popular and easy-to-use stretching exercise methods. Therefore, the purpose of this study was to determine the effect of static stretching exercise on hamstring muscle extensibility and pelvic tilt angle in hamstring tightness.

\section{Materials and Methods}

\subsection{Study design}

This research has a quasi-experimental study design pre-test and post-test control group design. In this study, two groups were used, group one was the treatment group, which was treated with static stretching exercises, and group two was the control group.

\subsection{Subjects}

The subjects of this study were 28 male students, who were divided into 2 groups. The treatment group and control group both consisted of 14 people.

Inclusion criteria: male students, aged 19-22 years, had a normal body mass index (BMI) and had hamstring tightness, indicated by an active knee extension (AKE) examination score of more than $15^{\circ}$.

Exclusion criteria: have a history of fractures of the lower limbs, pelvis, and spine, and have plates (implants) in the lower limbs.

\subsection{Measurement}

In this study, the hamstring muscle extensibility will be measured by examining active knee extension (AKE) and measuring the pelvic tilt angle, which will be evaluated in four weeks in both groups.

\subsection{Intervention}

The treatment group will be given static stretching intervention. This technique is performed with the subject lying supine, then the therapist passively lifts the subject's hip to $90^{\circ}$ flexion, then the therapist extends the subject's knee with the ankle in plantar flexion slowly, until the subject reports a strong but tolerable stretch in the posterior thigh. At this point, the stretch is maintained for 30 seconds and is repeated for 4 sets. The therapist observes the contralateral leg to keep the hip and knee in contact with the base and an extended position. This exercise was performed 3 times/week for 4 weeks (Ayala et al., 2013). 


\subsection{Statistical analysis}

The data from this study were analyzed using the SPSS V.22 application with a significance level of p < 0.05. The process of data analysis started from descriptive analysis, normality test, effect test (paired t-test), and correlation test (Pearson).

\section{Results}

Research subjects in both groups were analyzed based on age (20.79 \pm 0.802 vs $21.00 \pm 0.784)$, body mass index ( $23.49 \pm 0.50$ vs. $23.38 \pm 0.47)$, AKE value (27.14 \pm 5.78 vs. $26.64 \pm 4.75)$, and pelvic tilt angle (80.86 \pm 2.93 vs. $77.93 \pm 4.03$ ). From the results of the descriptive analysis, there was no statistically significant difference between the two groups (Table 1).

Table1. Sample descriptive data

\begin{tabular}{|c|c|c|}
\hline \multirow{2}{*}{ Characteristic } & $\begin{array}{c}\text { Treatment group } \\
(n=14)\end{array}$ & $\begin{array}{c}\text { Control group } \\
(\mathrm{n}=\mathbf{1 4})\end{array}$ \\
\hline & Mean \pm SD & Mean \pm SD \\
\hline Age (year) & $20,79 \pm 0,802$ & $21,00 \pm 0,784$ \\
\hline Body mass index $\left(\mathrm{kg} / \mathrm{m}^{2}\right)$ & $23,49 \pm 0,50$ & $23,38 \pm 0,47$ \\
\hline AKE test $\left(^{\circ}\right)$ & $27,14 \pm 5,78$ & $26,64 \pm 4,75$ \\
\hline Pelvic tilt angle $\left({ }^{\circ}\right)$ & $80,86 \pm 2,93$ & $77,93 \pm 4,03$ \\
\hline
\end{tabular}

Furthermore, the normality test was performed on both groups and both variables, AKE, and pelvic tilt angle. The normality test used the Shapiro-Wilk test (Table 2). Based on table 2, it was found that the AKE data and pelvic tilt angle data in both groups were normally distributed. Because all data are normally distributed, a paired t-test will be performed.

Table 2. Mean, standard deviation, and normality test of AKE and pelvic tilt angle in treatment and control group

\begin{tabular}{|c|c|c|c|c|c|c|}
\hline \multirow{2}{*}{\multicolumn{2}{|c|}{ Group }} & \multirow{3}{*}{$\begin{array}{c}\text { n } \\
14\end{array}$} & \multicolumn{2}{|c|}{ AKE } & \multicolumn{2}{|c|}{ Pelvic Tilt Angle } \\
\hline & & & Mean \pm SD $\left({ }^{\circ}\right)$ & p-value & Mean \pm SD $\left({ }^{\circ}\right)$ & \begin{tabular}{r|} 
p-value \\
Normality
\end{tabular} \\
\hline \multirow{2}{*}{$\begin{array}{l}\text { Treatment } \\
\text { group }\end{array}$} & Pre test & & $27,14 \pm 5,78$ & 0,063 & $80,86 \pm 2,93$ & 0,466 \\
\hline & Post test & 14 & $17,00 \pm 3,04$ & 0,555 & $80,71 \pm 2,99$ & 0,247 \\
\hline \multirow{2}{*}{ Control group } & Pre test & 14 & $26,64 \pm 4,75$ & 0,512 & $77,93 \pm 4,03$ & 0,152 \\
\hline & Post test & 14 & $26,64 \pm 4,58$ & 0,113 & $77,79 \pm 4,09$ & 0,129 \\
\hline
\end{tabular}

Paired t-test showed that the static stretching exercise had a significant effect on increasing the extensibility of the hamstring muscles $(\mathrm{p}<0.05)$ when compared to the control group (Table 3). Meanwhile, paired t-test shows that the static stretching exercise does not have a significant effect on the pelvic tilt angle $(p>0.05)$ as well as the control group (Table 4). 
Table 3. Paired t-test of AKE

\begin{tabular}{lllll}
\hline \multicolumn{2}{c}{ Group } & $\mathbf{n}$ & Mean \pm SD $\left({ }^{\circ}\right)$ & p-value \\
\cline { 3 - 5 } $\begin{array}{l}\text { Treatment } \\
\text { group }\end{array}$ & Pre test & 14 & $27,14 \pm 5,78$ & Paired t-test \\
\cline { 2 - 5 } Control group & Post test & 14 & $17,00 \pm 3,04$ & 1,000 \\
\cline { 2 - 5 } & Pre test & 14 & $26,64 \pm 4,75$ & 1,000 \\
\hline
\end{tabular}

Table 4. Paired t-test of pelvic tilt angle

\begin{tabular}{llllc}
\hline \multicolumn{2}{c}{ Kelompok } & $\mathbf{n}$ & Mean \pm SD $\left({ }^{\circ}\right)$ & p-value \\
\cline { 3 - 5 } $\begin{array}{l}\text { Treatment } \\
\text { group }\end{array}$ & Pre test & 14 & $80,86 \pm 2,93$ & Paired t-test \\
\cline { 2 - 5 } Control group & Post test & 14 & $80,71 \pm 2,99$ & 0,165 \\
\cline { 2 - 5 } & Pre test & 14 & $77,93 \pm 4,03$ & 0,165 \\
\hline
\end{tabular}

A correlation test was used to determine the correlation between the extensibility of the hamstring muscles and the pelvic tilt angle after the intervention in the static stretching treatment group. The correlation test was carried out using the Pearson test because the data were normally distributed. The correlation test using the Pearson test shows that there is no correlation between the hamstring muscle extensibility and pelvic tilt angle after the intervention in the static stretching treatment group $(\mathrm{p}>0.05)$ (Table 5).

Table 5. Correlation test (Pearson test) between AKE and the pelvic tilt angle

\begin{tabular}{llccc}
\hline \multirow{2}{*}{ Group } & Variable & n & Mean \pm SD $\left(^{\left({ }^{*}\right)}\right.$ & p-value \\
\cline { 3 - 4 } & & & & Pearson \\
\hline $\begin{array}{l}\text { Treatment } \\
\text { group }\end{array}$ & AKE & 14 & $17,00 \pm 3,04$ & 0,977 \\
\cline { 2 - 4 } & Pelvic tilt angle & & $80,71 \pm 2,99$ & \\
\hline
\end{tabular}

\section{Discussion}

Based on table 3, it was found that static stretching exercises had a significant effect on increasing the extensibility of the hamstring muscles. The results are following previous research by Lim et. al. (2014) which states that static stretching exercises can increase muscle activity significantly, which causes an increase in the extensibility of the hamstring muscles. This is due to changes in muscle activity and Hoffman reflexes that cause neurological changes in the muscles. Static stretching exercises also cause the elongation 
of the sarcomere and decrease of the cross-bridge which causes muscle tension. The mechanism of increasing muscle extensibility after static stretching exercise is probably due to autogenic inhibition, where muscles relax due to neuro-reflexive mechanisms increasing muscle length. The study also stated that in addition to neurological mechanisms, the increase in joint range of motion after stretching may also be due to an increase in stretch tolerance (Page, et. al., 2012).

Based on table 4, it was found that static stretching exercise did not have a significant effect on increasing the pelvic tilt angle in hamstring tightness. The results are following previous research by Shamsi et. al. (2020) which stated that static stretching and strengthening exercises given in 12 sessions for 4 weeks proved to have no impact on changes in the pelvic tilt angle. Similar research results were also obtained by Minarro et. al. (2012), it was stated that hamstring stretching exercises performed for 4 weeks only had the effect of increasing the length and extensibility of the hamstring muscles, but did not affect pelvic tilt either in a standing position or in trunk flexion in a sitting position with the knees flexed at $90^{\circ}$.

The results of this study prove that the extensibility of the hamstring muscles is not correlated with the pelvic tilt angle. This is following the results of previous research conducted by Fasuyi et. al. (2016) who concluded that there was no significant relationship between the length of the hamstring muscles and the pelvic tilt angle in individuals with or without low back pain. Similar results were also obtained by Shamsi et. al. (2020), who stated that the increase in the extensibility of the hamstring muscles was not correlated with the pelvic tilt angle. So that changes in the length of the hamstring muscles do not always affect the rotation of the pelvis (pelvic tilt). In this study, it was also stated that the increase in the length of the hamstring muscles may not always cause changes in the pelvic tilt angle.

\section{Conclusion}

This study proves that static stretching exercises have a significant effect on increasing the extensibility of the hamstring muscles. However, the static stretching exercise did not have a significant effect on increasing the pelvic tilt angle in the hamstring tightness condition. So that the increase in hamstring muscle extensibility is not correlated with changes in the pelvic tilt angle.

\section{Acknowledgments}

The authors are very thankful to the Faculty of Medicine, Universitas Airlangga.

\section{References}

Alshammari, F., Alzoghbieh, E., Abu Kabar, M., \& Hawamdeh, M. (2019). A novel approach to improve hamstring flexibility: A singleblinded randomized clinical trial. South African Journal of Physiotherapy, 75(1), 1-5.

Ayala, F., De Ste Croix, M., Sainz De Baranda, P., \& Santonja, F. (2013). Acute effects of static and dynamic stretching on hamstring eccentric isokinetic strength and unilateral hamstring to quadriceps strength ratios. Journal of Sports Sciences, 31(8), 831-839.

Braman, M. S. (2016). The Effect of Hamstring Lengthening on Pelvic Tilt and Lumbar Lordosis The Effect of Hamstring Lengthening on Pelvic Tilt and Lumbar Lordosis.

Fasuyi, F. O., Fabunmi, A. A., \& Adegoke, B. O. A. (2016). Hamstring muscle length and pelvic tilt range among individuals with and without low back pain. Journal of Bodywork \& Movement Therapies.

Hansberger, B. L., Loutsch, R., Hancock, C., Bonser, R., Zeigel, A., \& Baker, R. T. (2019). Evaluating the Relationship Between Clinical Assessments of Apparent Hamstring Tightness: a Correlational Analysis. International Journal of Sports Physical Therapy, 14(2),

Lim, K., N, H., \& J, K. (2014). Effects on Hamstring Muscle Extensibility, Muscle Activity, and Balance of Different Stretching Techniques. 
López-miñarro, P. A., Muyor, J. M., Belmonte, F., \& Alacid, F. (2012). Acute Effects of Hamstring Stretching on Sagittal Spinal Curvatures and Pelvic Tilt by. 31(March), 69-78.

Mhatre, B. S., Singh, Y. L., Tembhekar, J. Y., \& Mehta, A. (2013). Which is the better method to improve "perceived hamstrings tightness" - Exercises targeting neural tissue mobility or exercises targeting hamstrings muscle extensibility? International Journal of Osteopathic Medicine, 16(3)

Page, C. (2012). Clinical Commentary Current Concepts In Muscle Stretching. 7(1), 109-119.

Shamsi, M., Ph, D., Shahsavari, S., Safari, A., \& Mirzaei, M. (2020). Journal of Bodywork \& Movement Therapies A randomized clinical trial for the effect of static stretching and strengthening exercise on pelvic tilt angle in LBP patients. Journal of Bodywork \& Movement Therapies, 24(3), 15-20 